\title{
ALMOST PERIODIC MOTION IN COMPLETE SPACE
}

\author{
ANANT KUMAR \\ Satgharwa, P.0. Buniad Ganj \\ GAYA (INDIA), Pin-823003 \\ (Received December 17. 1985)
}

ABSTRACT. It is interesting that in a complete space an almost periodic motion is periodic if the null set $\emptyset$ is closed and if $\emptyset$ is not closed then every point of its trajectory is a limit point.

KEY WORDS AND PHRASES. Compact, periodic and almost periodic motions. 1980 AMS SUBJECT CLASSIFICATION CODE. 34 C35.

1. INTRODUCTION.

We studied "Poisson stable distal dynamical systems" in [1] where the word "compact" is missing from the statement and proof of theorem 2.7. It should be stated as theorem 3.1(below). Now by means of this theorem we shall establish an interesting relation (theorem 3.2) between almost periodic and periodic motions in a complete space $\mathrm{X}$.

2. DEFINITIONS AND NOTATIONS.

We shall follow definitions and notations of [1].

3. MAIN RESULTS.

3.1 THEOREM. Compact almost periodic motion is Poisson stable and distal.

3.2 THEOREM. In a complete space $X$ an almost periodic motion is periodic if the null set $\emptyset$ is closed in $X$ and if $\emptyset$ is not closed then $\gamma(x)=\Omega_{x}$ which is perfect and compact set.

PROOF. An almost periodic motion $\pi(x, t)$ is recurrent [2, theo 8.02 P.384] and if a recurrent motion is situated in a complete space then cly $(x)$ is compact minimal [2, theo 7.07 P.377]. Therefore the motion $\pi(x, t)$ is compact. Hence $\pi(x, t)$ is compact almost periodic motion therefore it is Poisson stable and distal ( 3.1 above). Thus $\gamma(x)$ is closed and perfect set [1, theo 2.1].

Now by [theo. VI.3 of 3, P.87], if $x$ is not periodic then

$$
\begin{aligned}
& \operatorname{cl}(\operatorname{cl} \gamma(x)-\gamma(x))=\operatorname{cl} \gamma(x)=\Omega_{x} . \\
& c 1(\gamma(x)-\gamma(x))=\gamma(x)=\Omega_{x} . \\
& c 1 \emptyset=\emptyset=\gamma(x)=\Omega_{x} \text { if } \emptyset \text { is closed set in } x .
\end{aligned}
$$

Which is impossible, as $\mathrm{x} \varepsilon \gamma(\mathrm{x})$ and in case of a compact motion $\Omega_{\mathrm{x}}$ is also non-empty [3, theo. II.8 P.20]. Therefore $x$ is periodic. But if $\emptyset$ is not closed then $\mathrm{c} 1 \emptyset=\gamma(\mathrm{x})=\Omega_{\mathrm{x}} \cdot \mathrm{l}$.

3.3 COROLLARY. If in theorem 3.2, $\mathrm{T}=\mathrm{R}$ (the set of reals) then $\gamma(\mathrm{x}$ ) is connected. 


\section{REFERENCES}

1. PRASAD, S.S. and KUMAR, A. "Stable P and Distal Dynamical Systems." Internat. J. Math. \& Math. Sci. Vol. 7 No. 1 (1984) 181-185.

2. NEMYTSKII, V.V. and STEPANOV, V.V. "Qualitative Theory of Differential Equations", University Press, 1960.

3. SELL, G.R. "Topological Dynamics and Ordinary Differential Equations", V.N.R. Mathematical Studies 33 (1971). 


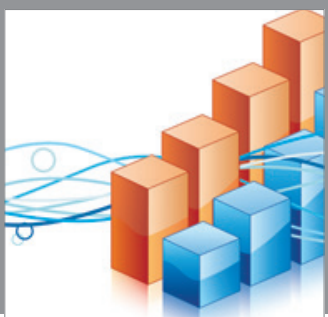

Advances in

Operations Research

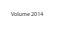

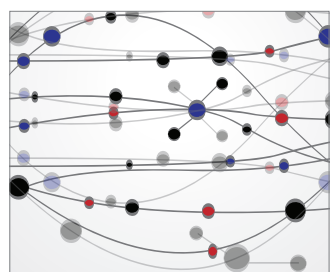

\section{The Scientific} World Journal
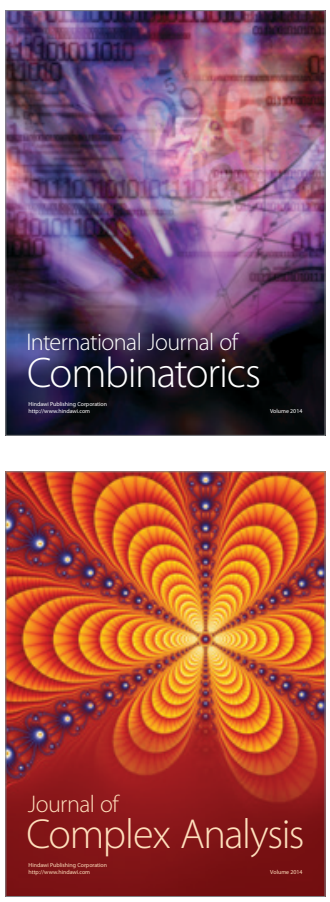

International Journal of

Mathematics and

Mathematical

Sciences
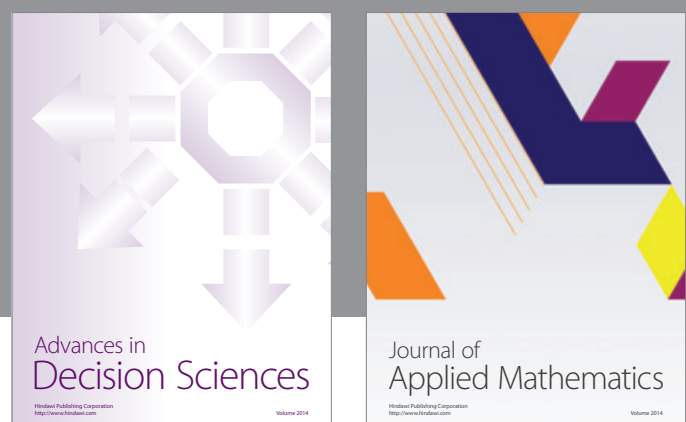

Journal of

Applied Mathematics
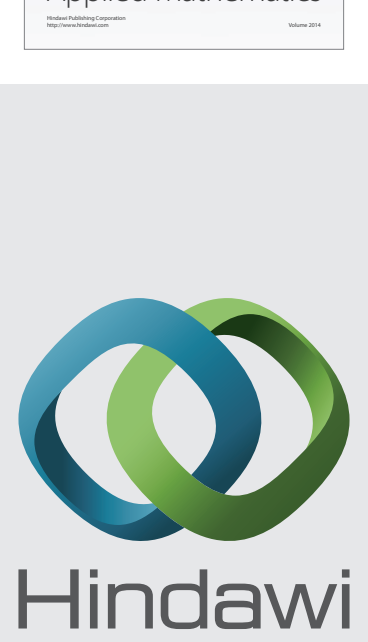

Submit your manuscripts at http://www.hindawi.com
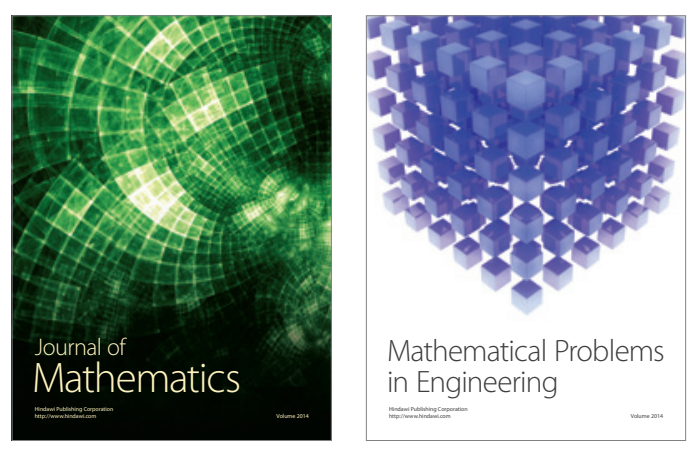

Mathematical Problems in Engineering
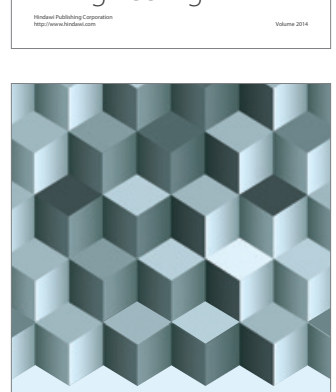

Journal of

Function Spaces
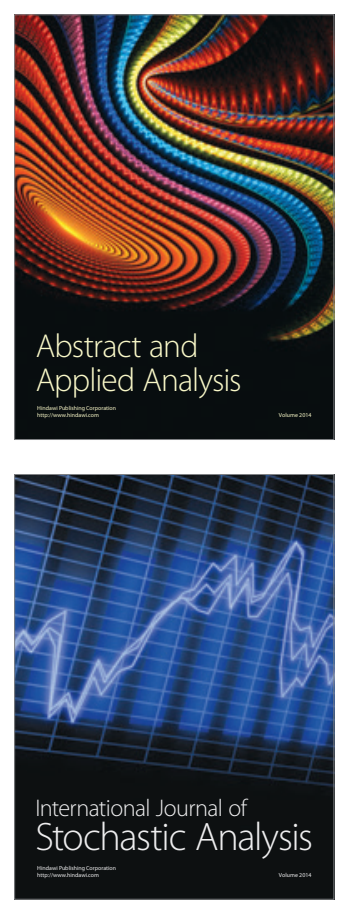

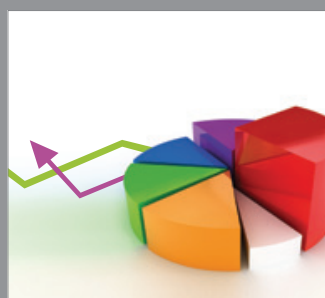

ournal of

Probability and Statistics

Promensencen
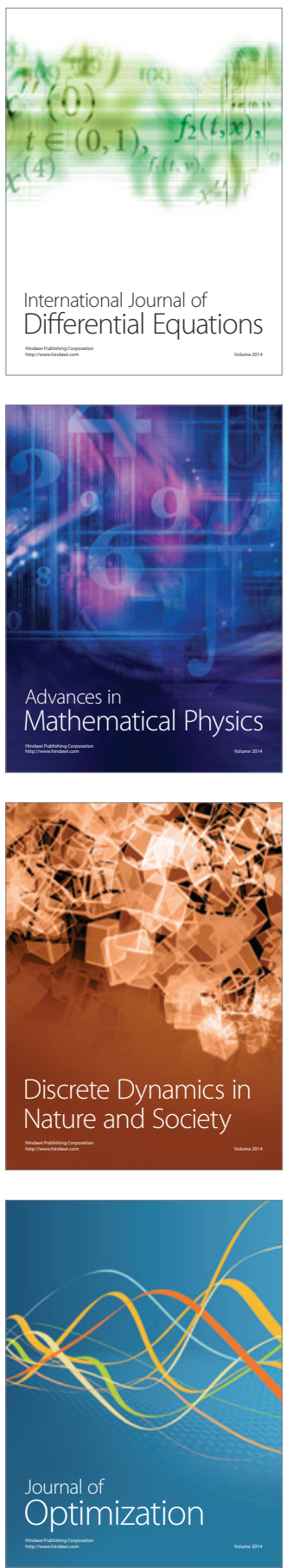